\title{
TIM-3 promotes the metastasis of esophageal squamous cell carcinoma by targeting epithelial-mesenchymal transition via the Akt/GSK-3//Snail signaling pathway
}

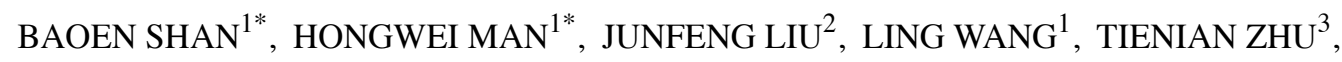 \\ MING MA ${ }^{4}$, ZHILI XV ${ }^{5}$, XINRAN CHEN ${ }^{1}$, XINGXIAO YANG ${ }^{6}$ and PENGFEI LI ${ }^{1}$ \\ ${ }^{1}$ Research Center and ${ }^{2}$ The Third Department of Thoracic Surgery, The Fourth Hospital of Hebei Medical University, \\ Shijiazhuang, Hebei 050011; ${ }^{3}$ Department of Oncology, Bethune International Peace Hospital, Shijiazhuang, \\ Hebei 050082; ${ }^{4}$ Department of Clinical Laboratory, The Fourth Hospital of Hebei Medical University, \\ Shijiazhuang, Hebei 050011; ${ }^{5}$ Department of Urology, The Third Hospital of Shijiazhuang, Shijiazhuang, Hebei 050011; \\ ${ }^{6}$ Department of Infection Control, The Fourth Hospital of Hebei Medical University, Shijiazhuang, Hebei 050011, P.R. China
}

Received February 9, 2016; Accepted March 18, 2016

DOI: $10.3892 /$ or.2016.4938

\begin{abstract}
T-cell immunoglobulin and mucin domain-containing protein-3 (TIM-3), a negative regulator of antitumor immune response, has been demonstrated to be involved in the onset and progression of several types of malignancies. The present study aimed to determine whether and how TIM-3 plays such a role in esophageal squamous cell carcinoma (ESCC). TIM-3 expression was analyzed by immunohistochemistry and real-time fluorescence quantitative PCR (qRT-PCR) in ESCC and matched adjacent normal tissues. Functional experiments in vitro were performed to elucidate the effect of TIM-3 knockdown on the proliferation, apoptosis, migration, invasion and epithelial-mesenchymal transition (EMT) in Eca109 and TE-1 cell lines. Our data revealed that TIM-3 expression was significantly elevated at both the mRNA and protein levels in ESCC tissues compared with the levels in the matched adjacent normal tissues (both $\mathrm{P}<0.001$ ). TIM-3 expression was significantly associated with lymph node metastasis $(\mathrm{P}=0.008)$, tumor-node-metastasis (TNM) stage $(\mathrm{P}=0.042)$ and depth of tumor invasion $(\mathrm{P}=0.042)$. In addition, we observed a strong correlation between high TIM-3 expression and a worse overall survival of ESCC patients $(\mathrm{P}=0.001)$. Functional study demonstrated that TIM-3 knockdown
\end{abstract}

Correspondence to: Professor Baoen Shan, Research Center, The Fourth Hospital of Hebei Medical University, 12 Jiankang Road, Shijiazhuang, Hebei 050011, P.R. China

E-mail: baoenshan@hotmail.com

*Contributed equally

Key words: T-cell immunoglobulin and mucin domain-containing protein-3, esophageal squamous cell carcinoma, epithelial-mesenchymal transition, metastasis, prognosis markedly inhibited proliferation, migration and invasion of ESCC cell lines without affecting apoptosis. In addition, TIM-3 depletion was associated with downregulation of matrix metalloproteinase (MMP)-9 and upregulation of tissue inhibitor of metalloproteinase (TIMP)-1, and with reversion of EMT, as reflected by higher levels of the epithelial marker E-cadherin and lower levels of the mesenchymal markers $\mathrm{N}$-cadherin and vimentin. Further study found that TIM-3 depletion suppressed the signaling pathway involving $\mathrm{p}-\mathrm{Akt}$, p-GSK-3 $\beta$ and Snail. Taken together, these results suggest that TIM-3 is a novel therapeutic target and prognostic biomarker for ESCC and promotes metastasis of ESCC by inducing EMT via, at least partially, the Akt/GSK-3 $\beta /$ Snail signaling pathway.

\section{Introduction}

Esophageal cancer is a common aggressive malignancy characterized by late diagnosis and early metastasis $(1,2)$. Esophageal cancer is the eighth most common cancer and sixth most common cause of cancer-related deaths worldwide, with an estimated 455,800 new cases and 400,200 deaths occurring in 2012 alone $(3,4)$. In 2015, an estimated 16,980 individuals were diagnosed with esophageal cancer in the USA, and 15,590 individuals succumbed to the disease, making it the ninth leading cause of cancer-related deaths in that country (5). Esophageal cancers are histologically classified as squamous cell carcinoma (SCC) or adenocarcinoma (3). Esophageal squamous cell carcinoma (ESCC) represents a predominant type of esophageal cancer, accounting for approximately $90 \%$ of all esophageal cancers (6). Despite improvements in surgical approaches combined with chemotherapy and/or radiotherapy, the prognosis of ESCC patients remains unsatisfactory, with 5-year survival rates of patients with stage III disease ranging from 10 to $15 \%$ (7). Therefore, effective treatments against ESCC are needed, such as treatments targeting molecules and pathways specifically activated in this disease. 
T-cell immunoglobulin and mucin domain-containing protein-3 (TIM-3), also known as hepatitis A virus cellular receptor 2 , is one of the members of the TIM family (8). TIM-3 is selectively expressed on IFN- $\gamma$-producing CD $4^{+}$ $\mathrm{T}$ helper 1 (Th1) and $\mathrm{CD}^{+} \mathrm{T}$ cytotoxic 1 (Tc1) $\mathrm{T}$ cells, but not on Th2 cells (9). Numerous studies have verified that TIM-3 is involved in immune regulation of tumors. Interaction between TIM-3 and its ligand, galectin-9, triggers cell death in Th1 cells and induces peripheral tolerance (10). Indeed, the TIM-3/galectin-9 signaling pathway mediates T-cell senescence and predicts poor survival in patients with hepatitis $B$ virus-associated hepatocellular carcinoma (11). Furthermore, previous studies have revealed an important role of TIM-3 in T-cell exhaustion in tumors. In patients with advanced melanoma, TIM- $3^{+}$PD- $1^{+}$NY-ESO-1-specific $\mathrm{CD}^{+} \mathrm{T}$ cells exhibit a highly exhausted phenotype, and co-blockade of TIM-3 and PD-1 signaling pathways contributes to restore production of effector cytokines and proliferation of NY-ESO-1-specific $\mathrm{CD}^{+} \mathrm{T}$ cells (12). Recently, several studies have found that TIM-3 is overexpressed in several types of human tumors, such as lung (13), prostate (14), gastric (15) and bladder urothelial (16) cancer, and its overexpression is associated with poor prognosis in these cancers.

Although TIM-3 plays an important role in a variety of tumors, the expression and biological functions of TIM-3 in ESCC remain unknown. In the present study, we sought to detect the expression of TIM-3 in human ESCC tissues and evaluate the clinicopathological significance of TIM-3 expression in ESCC. Furthermore, we explored the effects of TIM-3 on the proliferation, apoptosis, migration and invasion of ESCC cells, and the possible signaling pathways involved.

\section{Materials and methods}

Patients and tissue specimens. A total of 64 patients who underwent surgical resection at the Fourth Hospital of Hebei Medical University between January 2006 and January 2008 were enrolled in this study. All patients were diagnosed with ESCC based on pathology, and none of the patients received radiotherapy, chemotherapy or biological therapy before surgery. Complete clinical data and follow-up examinations were available for all patients. The study included 48 men and 16 women (median age, 57.5 years; range, 37-78 years). The median follow-up was 31 months, with a range from 7 to 105 months. Tumor-node-metastasis (TNM) stage was determined using criteria of the World Health Organization (WHO) and the International Union Against Cancer (UICC). Tumor masses as well as adjacent normal tissues, which were at least $5 \mathrm{~cm}$ distal to tumor margins, were snap-frozen in liquid nitrogen for quantitative real-time reverse transcriptase-PCR (qRT-PCR) assay or fixed in $10 \%$ neutral formalin solution for immunohistochemistry. This study protocol was approved by the Ethics Department of the Fourth Hospital of Hebei Medical University (Shijiazhuang, China), and informed consent was obtained from patients or their families.

Cell lines and culture. Human esophageal squamous cell lines Eca109, TE-1, TE-13, KYSE30, and KYSE170 were purchased from the Cell Bank of the Chinese Academy of Sciences (Shanghai, China). Cell lines were cultured in RPMI-1640 (Gibco, Carlsbad, CA, USA) supplemented with $25 \mathrm{mM}$ HEPES, $2 \mathrm{mM}$ L-glutamine, $10 \%$ fetal bovine serum (FBS; Sijiqing, Hangzhou, China), $100 \mathrm{U} / \mathrm{ml}$ penicillin and $100 \mathrm{~g} / \mathrm{ml}$ streptomycin. All cells were incubated at $37^{\circ} \mathrm{C}$ in a humidified atmosphere with $5 \% \mathrm{CO}_{2}$.

$q R T-P C R$. Total RNA from tissue specimens and cultured cells was extracted using TRIzol (Invitrogen, Carlsbad, CA, USA) according to the manufacturer's instructions. RNA was reverse-transcribed into cDNA using the RevertAid First Strand cDNA Synthesis kit (Thermo Fisher Scientific, Shanghai, China) according to the manufacturer's instructions. Amplification of the generated cDNA was performed on Mx3005P Real-Time PCR Cycler (Stratagene Corp.; Agilent Technologies, Inc., USA) using SYBR-Green PCR Master Mix (Promega, Madison, WI, USA). Levels of mRNA were normalized to those of glyceraldehyde-3-phosphate dehydrogenase (GAPDH). The primer sequences used in this study are shown in Table I. The PCR conditions were $95^{\circ} \mathrm{C}$ for $10 \mathrm{~min}$, followed by 40 cycles of $95^{\circ} \mathrm{C}$ for $15 \mathrm{sec}, 60^{\circ} \mathrm{C}$ for $30 \mathrm{sec}$, and $72^{\circ} \mathrm{C}$ for $30 \mathrm{sec}$. Verification of specific product amplification was determined by melting curve analysis. Relative expression of TIM-3 mRNA in carcinoma tissues and matched adjacent normal tissues was calculated using the $2^{-\Delta \mathrm{Ct}} \operatorname{method}(17)$. The fold change of each mRNA was evaluated using the $2^{-\Delta \Delta \mathrm{Ct}}$ method (18).

Immunohistochemistry. Formalin-fixed tissues were embedded in paraffin, and sections ( $4 \mu \mathrm{m}$ thick) were cut from each paraffin block. Paraffin sections were dewaxed in xylene twice for $15 \mathrm{~min}$ each and rehydrated through a graduated series of alcohol solutions ( 5 min per step). Antigen was retrieved by boiling sections in citrate buffer ( $\mathrm{pH}$ 6.0) for $5 \mathrm{~min}$ in a pressure cooker, and endogenous peroxidase activity was blocked by incubation in $3 \% \mathrm{H}_{2} \mathrm{O}_{2}$ for $20 \mathrm{~min}$. Sections were incubated at $37^{\circ} \mathrm{C}$ for $60 \mathrm{~min}$ in $10 \%$ normal goat serum to block non-specific background staining, and incubated overnight at $4^{\circ} \mathrm{C}$ with rabbit anti-human TIM-3 polyclonal antibody (1:100 dilution; Abcam, Southampton, UK). Subsequently, the sections were incubated with a biotinylated secondary antibody, followed by the streptavidin-peroxidase complex. Chromogen [3,3'-diaminobenzidine (DAB)] was added, after which sections were counterstained with Mayer's hematoxylin. Negative control sections were treated as described, except that primary antibody was omitted.

Evaluation of TIM-3 protein expression. Two pathologists blinded to clinical information independently assessed the immunohistochemistry results. Five visual fields were randomly selected in each section, and 200 tumor cells were counted in each visual field at x200 magnification. Cells were regarded as positive if the cell membrane and/or cytoplasm stained brown. The percentage of positive cells and the intensity of staining were evaluated in all sections, and the final score for each section was derived from the multiplication of the two. The scoring system for the percentage of positive cells was as follows: 1 point, $\leq 33 \%$; 2 points, $>33$ to $\leq 66 \%$; 3 points, $>66 \%$. The scoring system for staining intensity was as follows: 1 point, absent/weak staining; 2 points, moderate 
Table I. Sequences of the qRT-PCR primers used for mRNA analysis.

\begin{tabular}{|c|c|c|c|c|}
\hline \multirow{2}{*}{$\frac{\text { Genes }}{\text { TIM-3 }}$} & \multicolumn{2}{|r|}{ Primer sequences } & \multirow{2}{*}{$\frac{\mathrm{AT}\left({ }^{\circ} \mathrm{C}\right)}{60}$} & \multirow{2}{*}{$\frac{\text { Product size }(\mathrm{bp})}{172}$} \\
\hline & $\mathrm{F}$ & 5'-CGCTGAGTACGTCGTGGAGTC-3' & & \\
\hline & $\mathrm{R}$ & 5'-CTGATGATCTTGAGGCTGTTGTC-3' & & \\
\hline \multirow[t]{2}{*}{ MMP-9 } & $\mathrm{F}$ & 5'-GGGCACTCCCAATAA-3' & \multirow[t]{2}{*}{60} & \multirow[t]{2}{*}{93} \\
\hline & $\mathrm{R}$ & 5'-GATGCTAGGCTTCCTG-3' & & \\
\hline \multirow[t]{2}{*}{ TIMP-1 } & $\mathrm{F}$ & 5'-ACCAGACCACCTTATACCAGCG-3' & \multirow[t]{2}{*}{60} & \multirow[t]{2}{*}{395} \\
\hline & $\mathrm{R}$ & 5'-GGACTGGAAGCCCTTTTCAGAG-3' & & \\
\hline \multirow[t]{2}{*}{ E-cadherin } & $\mathrm{F}$ & 5'-CCGCCATCGCTTACA-3' & \multirow[t]{2}{*}{60} & \multirow[t]{2}{*}{220} \\
\hline & $\mathrm{R}$ & 5'-GGCACCTGACCCTTGTA-3' & & \\
\hline \multirow{2}{*}{$\mathrm{N}$-cadherin } & $\mathrm{F}$ & 5'-GAAAGACCCATCCACG-3' & \multirow[t]{2}{*}{60} & \multirow[t]{2}{*}{217} \\
\hline & $\mathrm{R}$ & 5'-CCTGCTCACCACCACTA-3' & & \\
\hline \multirow[t]{2}{*}{ Vimentin } & $\mathrm{F}$ & 5'-AAGGCGAGGAGAGCAGGATT-3' & \multirow[t]{2}{*}{60} & \multirow[t]{2}{*}{180} \\
\hline & $\mathrm{R}$ & 5'-GGTCATCGTGATGCTGAGAAG-3' & & \\
\hline \multirow[t]{2}{*}{ GAPDH } & $\mathrm{F}$ & 5'-CAGATACTGGCTAAATGGGGAT-3' & \multirow[t]{2}{*}{60} & \multirow[t]{2}{*}{162} \\
\hline & $\mathrm{R}$ & 5'-ACCTTGGCTGGTTTGATGAC-3' & & \\
\hline
\end{tabular}

AT, annealing temperature; TIM-3, T-cell immunoglobulin and mucin domain-containing protein-3; MMP, matrix metalloproteinase; TIMP, tissue inhibitor of metalloproteinase; GAPDH, glyceraldehyde-3-phosphate dehydrogenase; F, forward; R, reverse.

staining; 3 points, strong staining. Sections with a final overall score of $\leq 3$ were classified as the TIM-3 low expression group; other sections were classified as the TIM- 3 high expression group (19).

Western blotting. To extract total protein, the cells were collected and lysed in RIPA buffer supplemented with PMSF (Beyotime, Shanghai, China) at $4^{\circ} \mathrm{C}$ for $30 \mathrm{~min}$. Total protein concentrations were measured using the BCA Protein Assay kit (Beyotime). Equal amounts of protein were separated by $10 \%$ SDS-PAGE and transferred to polyvinylidene fluoride (PVDF) membranes. The membranes were blocked with 5\% non-fat dry milk at room temperature for $1 \mathrm{~h}$ and incubated at $4^{\circ} \mathrm{C}$ overnight with the respective antibodies: rabbit anti-GAPDH, TIM-3, matrix metalloproteinase (MMP)-9, tissue inhibitor of metalloproteinase (TIMP)-1, E-cadherin, $\mathrm{N}$-cadherin, vimentin, Snail, Akt, GSK-3 $\beta$, p-Akt, and p-GSK-3 $\beta$ (Abcam). The membranes were washed with TBST three times for $5 \mathrm{~min}$ each, and incubated with horseradish peroxidase-conjugated secondary antibody for $1 \mathrm{~h}$ at room temperature. The bands were quantitated in grayscale using Image-Pro Plus software 6.0 (Media Cybernetics, Silver Spring, MD, USA).

Plasmid transfection and establishment of stable cell lines. To knock down TIM-3 expression in the Eca109 and TE-1 cells, shRNA targeting TIM-3 or negative control shRNA (Applied BioProbes; GeneCopoeia Co.) was transfected into Eca109 and TE-1 cells using Lipofectamine 2000 (Invitrogen) according to the manufacturer's instructions. The sequences of the specific shRNA against TIM-3 were as follows: forward, 5'-GGGACTCTAGATTGGCCA ATG-3' and reverse, 5'-TAAGACTACGGCGCGAAGC-3'. Stable transfected clones were selected for 2 weeks using
$3 \mu \mathrm{g} / \mathrm{ml}$ puromycin (Sigma, St. Louis, MO, USA), and monoclonal cells were picked up with tips. Subsequently, the resistant clones were amplified in conventional medium with $3 \mu \mathrm{g} / \mathrm{ml}$ puromycin.

MTS assay. Cell viability was evaluated using the 3-(4,5-dimethylthiazol-2-yl)-5-(3-carboxymethoxyphenyl)-2(4-sulphophenyl)-2H-tetrazolium (MTS) assay. Cells were seeded into 96 -well plates at a density of $4 \times 10^{3}$ cells/well for 24,48 or $72 \mathrm{~h}$. At each time point, $20 \mu \mathrm{l}$ of MTS solution (Promega) was added to each well and incubated at $37^{\circ} \mathrm{C}$ for $3 \mathrm{~h}$ in the dark. The absorbance of each well was measured at $492 \mathrm{~nm}$ using a spectrophotometer (Thermo Fisher Scientific). Each experiment included six replications and was repeated three times.

Colony formation assay. Cells were seeded at a density of $3 \times 10^{3}$ cells/well in 6 -well culture plates and cultured at $37^{\circ} \mathrm{C}$ for 1 week. Colonies were washed with phosphate-buffered saline (PBS), fixed with $4 \%$ neutral formalin and stained with $0.1 \%$ crystal violet (Sigma). Colonies containing $>50$ cells were counted. Each experiment was performed in triplicate.

Migration and invasion assays. Cell migration and invasion assays were performed in 24-well Transwell cell culture chambers (Corning, Cambridge, MA, USA) containing a polycarbonate membrane filter with $8.0-\mu \mathrm{m}$ pores. For the cell invasion assay, $30 \mu 1$ of Matrigel (1:7 dilution; Becton-Dickinson, San Jose, CA, USA) was added to the upper chamber and dried overnight at $37^{\circ} \mathrm{C}$ in a $5 \% \mathrm{CO}_{2}$ incubator. A total of $5 \times 10^{4}$ cells were resuspended in $200 \mu \mathrm{l}$ serum-free RPMI-1640 medium and seeded into the upper chamber. The lower chamber was filled with $600 \mu \mathrm{l}$ of RPMI-1640 medium containing 20\% FBS. After incubation 
A

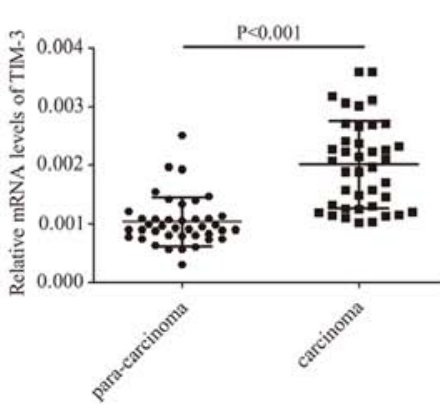

B

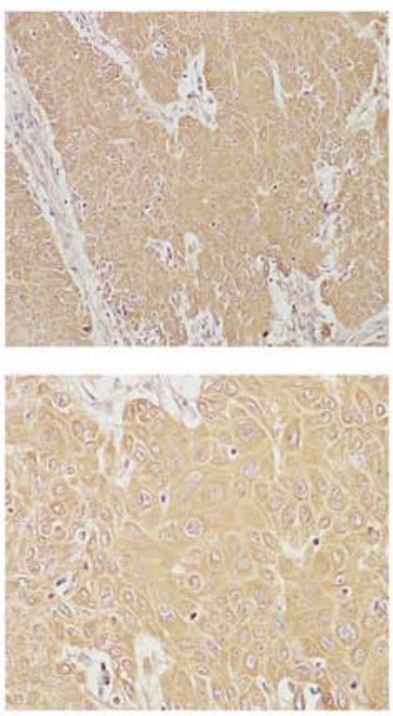

C
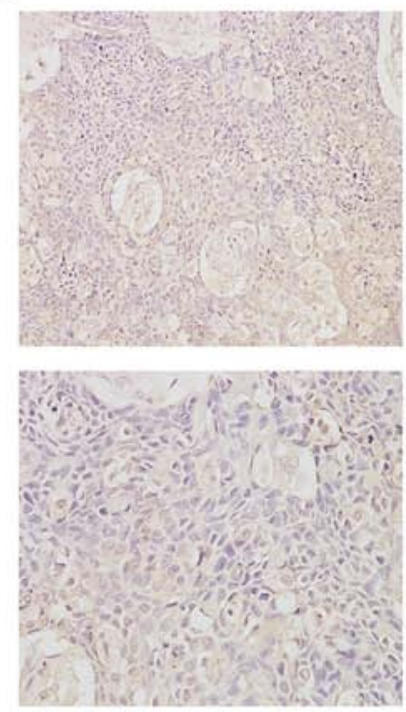

D
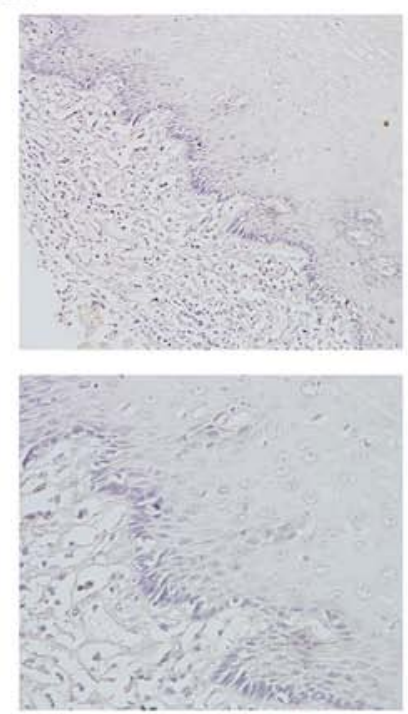

Figure 1. TIM-3 is upregulated in ESCC tissues. (A) Relative mRNA expression of TIM-3 in ESCC and adjacent normal tissues was analyzed using qRT-PCR. (B-D) Expression of TIM-3 protein in ESCC and adjacent normal tissues was analyzed using immunohistochemistry. (B) High expression of TIM-3 in ESCC tissues. (C) Low expression of TIM-3 in ESCC tissues. (D) Undetectable TIM-3 expression in adjacent normal tissues. Upper panels, x200 magnification; lower panels, x400 magnification. TIM-3, T-cell immunoglobulin and mucin domain-containing protein-3; ESCC, esophageal squamous cell carcinoma.

at $37^{\circ} \mathrm{C}$ with $5 \% \mathrm{CO}_{2}$ for $24 \mathrm{~h}$, non-invading cells still on the upper side of the chamber were wiped with a cotton swab. Invaded cells on the bottom of the polycarbonate membrane were fixed for $20 \mathrm{~min}$ with $4 \%$ neutral formalin, and stained for 30 min with $0.1 \%$ crystal violet. For the cell migration assay, we performed a similar procedure as described above, except that the upper chamber was not coated with Matrigel. Each experiment was performed in triplicate. The number of cells that migrated or invaded through the polycarbonate membrane was counted in five randomly selected visual fields at x200 magnification using a high-resolution inverted microscope.

Detection of apoptosis by flow cytometry. Cells were collected and resuspended in $100 \mu \mathrm{l} 1 \mathrm{X}$ binding buffer at a density of $1 \times 10^{6}$ cells $/ \mathrm{ml}$. Cell apoptosis was detected using the Annexin V-PE/7-AAD Apoptosis Detection kit (Becton-Dickinson) according to the manufacturer's instructions. The Annexin V-PE and 7-AAD stained cells were examined by flow cytometry on a BD FACScalibur (BD Biosciences).

Statistical analysis. All statistical analyses were analyzed using SPSS 17.0 (IBM, Chicago, IL, USA), and figures were generated using GraphPad Prism 5.0 (GraphPad Software, Inc., La Jolla, CA, USA). Differences in mean values between groups were assessed for significance using the Student's t-test or one-way analysis of variance (ANOVA). Differences in TIM-3 expression between ESCC and matched adjacent normal tissues were assessed using the $\chi^{2}$ test. The relationships between TIM-3 expression and clinicopathological features were analyzed using the $\chi^{2}$ test or Fisher's exact test. Overall survival was calculated using the Kaplan-Meier method, and the differences between groups were assessed for significance using the log-rank test. Data are presented as means \pm SD from at least three independent experiments. $\mathrm{P}<0.05$ was considered statistically significant.

\section{Results}

TIM-3 is upregulated in ESCC tissues. TIM-3 mRNA levels were analyzed by qRT-PCR in 40 pairs of ESCC and matched adjacent normal tissues. The relative mRNA expression of TIM-3 was significantly higher in the tumor tissues than that in the adjacent normal tissues $(0.002 \pm 0.0007$ vs. $0.001 \pm 0.0004$; $\mathrm{P}<0.001$, Fig. 1A).

TIM-3 protein levels were analyzed by immunohistochemistry in 64 pairs of ESCC and adjacent normal tissue specimens. TIM-3 protein was localized predominantly in the cellular membrane and the cytoplasm of tumor cells (Fig. 1B-D). TIM-3-positive staining (overall score $>1$ ) was present in 55 of the 64 ESCC tissue sections (85.9\%), compared to only 7 of the 64 normal tissue sections (10.9\%). Of the 55 TIM-3-positive ESCC samples, 19 (34.5\%) showed low TIM-3 expression (overall score $\leq 3$ ), and $36(65.5 \%)$ showed high TIM-3 expression (overall score $>3$ ), whereas all 7 of the TIM-3-positive normal tissue samples showed low TIM-3 expression. Statistical analysis of these results indicated that TIM-3 protein expression was significantly higher in the ESCC tissues than that in the adjacent normal tissues $(\mathrm{P}<0.001$, Table II).

Association between TIM-3 expression and clinicopathological parameters. We analyzed the correlations between TIM-3 protein expression and numerous clinicopathological parameters, including age, gender, tumor size, TNM stage, lymphatic metastasis, and depth of tumor invasion (Table III). Our results revealed that the expression of TIM-3 protein was 
Table II. Expression of TIM-3 in ESCC and matched adjacent normal tissues.

\begin{tabular}{lcccc}
\hline & & \multicolumn{2}{c}{ TIM-3 expression } & \\
\cline { 3 - 4 } Tissue types & Cases & Negative & Positive & P-value \\
\hline Tumor tissues & 64 & 9 & 55 & $<0.001$ \\
$\begin{array}{l}\text { Matched normal } \\
\text { tissues }\end{array}$ & 64 & 57 & 7 & \\
\hline
\end{tabular}

TIM-3 expression was detected by immunohistochemistry and the difference between the two groups was estimated by $\chi^{2}$ test. ${ }^{a} \mathrm{P}<0.001$ indicates statistical significance. TIM-3, T-cell immunoglobulin and mucin domain-containing protein-3; ESCC, esophageal squamous cell carcinoma.

significantly associated with TNM stage $(\mathrm{P}=0.008)$, lymph node metastasis $(\mathrm{P}=0.042)$ and depth of tumor invasion $(\mathrm{P}=0.042)$. However, no significant differences were observed between the TIM-3 protein expression and the other clinicopathological parameters.

TIM-3 expression is associated with poor prognosis in ESCC patients. Patients were divided into two groups (TIM-3 low expression group or TIM-3 high expression group) as described in the 'Materials and methods' section. Kaplan-Meier survival analysis indicated that patients in the TIM-3 high expression group had a significantly shorter overall survival than patients in the TIM-3 low expression group ( $\mathrm{P}=0.001$, Fig. 2$)$. The overall 5-year survival rate for patients in the TIM-3 high expression group was $9 \%$ with a median survival time of 22 months, while the overall 5-year survival rate for patients in the TIM-3 low expression group was $19.2 \%$ with a median survival time of 41 months.

shRNA effectively inhibits TIM-3 expression in ESCC cell lines. The expression levels of TIM-3 mRNA and protein in various ESCC cell lines, including KYSE30, TE-13, Eca109, KYSE170 and TE-1, were evaluated by qRT-PCR and western blotting, respectively. These results showed that TIM-3 expression was relatively highest in the Eca109 and TE-1 cell lines (Fig. 3A and B). Therefore, we selected these two cell lines to knock down TIM-3 expression and explore the effects on cancer cell function. We established shRNA-mediated stable Eca109-shTIM-3 and TE-1-shTIM-3 cells, and their respective negative controls (Eca109-NC and TE-1-NC cells). Transfection efficiency was evaluated by qRT-PCR and western blotting. The mRNA and protein levels of TIM-3 were markedly decreased in the Eca109-shTIM-3 and TE-1-shTIM-3 cells than levels in their corresponding parental or negative control cells $(\mathrm{P}<0.001$, Fig. 3C-F).

Downregulation of TIM-3 inhibits cell proliferation without affecting apoptosis. Effects of TIM-3 knockdown on ESCC proliferation were examined by MTS and colony formation assays. In the MTS assay, the absorbance at $492 \mathrm{~nm}$ was significantly lower in the Eca109-shTIM-3 and TE-1-shTIM-3 cells than those in their corresponding parental or negative control
Table III. Correlation of TIM-3 expression and clinicopathological parameters of the ESCC cases.

\begin{tabular}{|c|c|c|c|c|c|}
\hline \multirow[b]{2}{*}{ Characteristics } & \multirow[b]{2}{*}{ Cases } & \multicolumn{2}{|c|}{$\begin{array}{c}\text { TIM-3 } \\
\text { expression }\end{array}$} & \multirow[b]{2}{*}{$\chi^{2}$} & \multirow[b]{2}{*}{ P-value } \\
\hline & & Low & High & & \\
\hline Gender & & & & 1.354 & 0.244 \\
\hline Male & 48 & 23 & 25 & & \\
\hline Female & 16 & 5 & 11 & & \\
\hline Age (years) & & & & 0.301 & 0.583 \\
\hline$\leq 55$ & 25 & 12 & 13 & & \\
\hline$>55$ & 39 & 16 & 23 & & \\
\hline Tumor size $(\mathrm{cm})$ & & & & 0.000 & 1.000 \\
\hline$\leq 5$ & 32 & 14 & 18 & & \\
\hline$>5$ & 32 & 14 & 18 & & \\
\hline TNM stage & & & & 10.653 & $0.008^{\mathrm{a}, \mathrm{b}}$ \\
\hline I & 10 & 9 & 1 & & \\
\hline II & 32 & 11 & 21 & & \\
\hline III & 20 & 7 & 13 & & \\
\hline IV & 2 & 1 & 1 & & \\
\hline $\begin{array}{l}\text { Lymph node } \\
\text { metastasis }\end{array}$ & & & & 4.135 & $0.042^{\mathrm{c}}$ \\
\hline Negative & 39 & 21 & 18 & & \\
\hline Positive & 25 & 7 & 18 & & \\
\hline $\begin{array}{l}\text { Depth of tumor } \\
\text { invasion }\end{array}$ & & & & 4.136 & $0.042^{\mathrm{c}}$ \\
\hline $\mathrm{pT}_{1}-\mathrm{pT}_{2}$ & 19 & 12 & 7 & & \\
\hline $\mathrm{pT}_{3}-\mathrm{pT}_{4}$ & 45 & 16 & 29 & & \\
\hline
\end{tabular}

${ }^{\mathrm{a}} \mathrm{P}<0.01$, compared with other items in the same index. ${ }^{\mathrm{b}}$ Fisher's exact test. ${ }^{c} \mathrm{P}<0.05$, compared with other items in the same index. TIM-3, T-cell immunoglobulin and mucin domain-containing protein-3; ESCC, esophageal squamous cell carcinoma; TNM, tumor-node-metastasis.

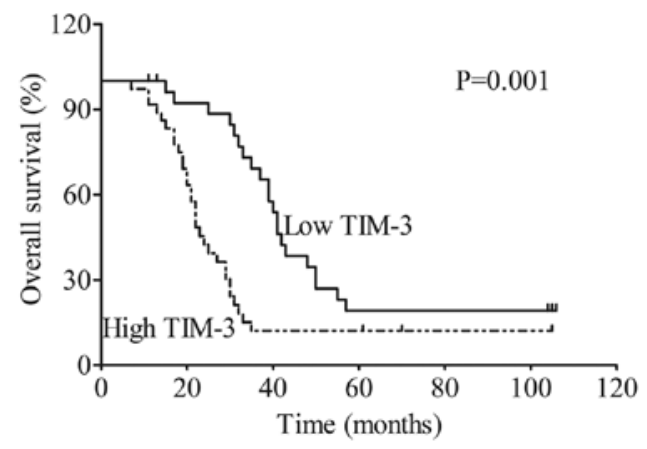

Figure 2. Relationship between overall survival rate and TIM-3 expression in ESCC tissues ( $\mathrm{P}=0.001, \log$-rank test). TIM-3, T-cell immunoglobulin and mucin domain-containing protein-3; ESCC, esophageal squamous cell carcinoma.

cells at 24, 48 and $72 \mathrm{~h}(\mathrm{P}<0.01$, Fig. $4 \mathrm{~A}$ and $\mathrm{C})$. Consistent with these results, colony formation potential was significantly decreased in the Eca109-shTIM-3 and TE-1-shTIM-3 
A

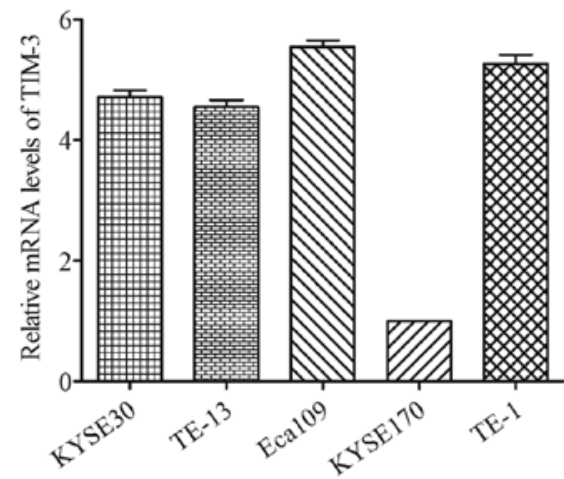

C

E
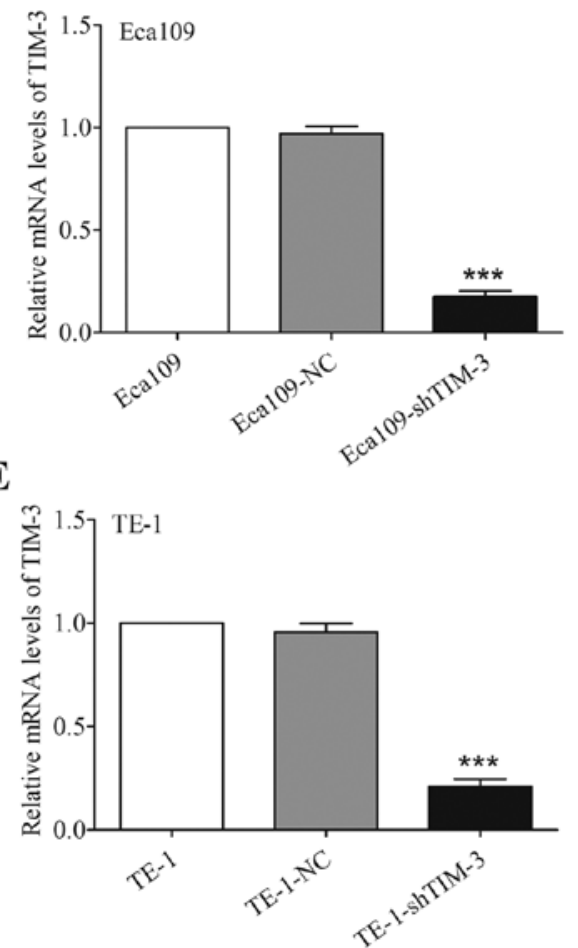

B

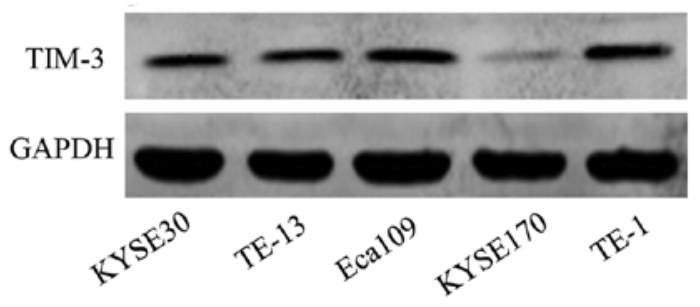

D

TIM-3

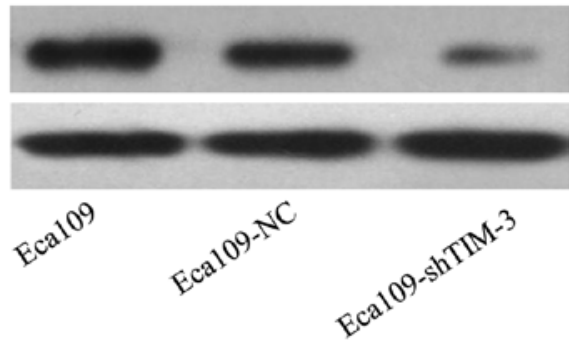

F

TIM-3

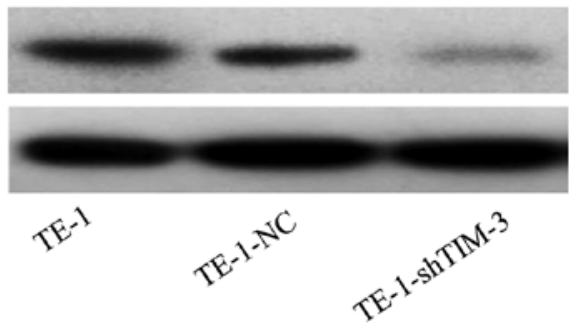

Figure 3. TIM-3 expression in various ESCC cell lines and transfection efficiency of TIM-3 shRNA. (A and B) TIM-3 expression was analyzed (A) at the mRNA level using qRT-PCR and (B) at the protein level using western blotting in five ESCC cell lines (KYSE30, TE-13, Eca109, KYSE170, TE-1), (C and D) The transfection efficiency of TIM-3 shRNA in the Eca109 cells was assessed by detecting (C) TIM-3 mRNA levels using qRT-PCR and (D) TIM-3 protein levels using western blotting. (E and F) The same experiments were also performed in TE-1 cells. GAPDH was used for normalization. Data are shown as means $\pm \mathrm{SD}$. ${ }^{* * *} \mathrm{P}<0.001$ vs. the NC group. TIM-3, T-cell immunoglobulin and mucin domain-containing protein-3; ESCC, esophageal squamous cell carcinoma; GAPDH, glyceraldehyde-3-phosphate dehydrogenase; NC, negative control.

cells $(\mathrm{P}<0.001$, Fig. 4B and $\mathrm{D})$. In contrast to its effects on proliferation, TIM-3 knockdown did not significantly affect cell apoptosis based on an Annexin V-PE/7-AAD staining assay (Fig. 4E).

Downregulation of TIM-3 inhibits the migratory and invasive potential of ESCC cells. To characterize the effects of TIM-3 knockdown on the migration and invasion of ESCC cells, we performed Transwell migration and Matrigel invasion assays. In the Transwell migration assay, the number of Eca109-shTIM-3 cells which migrated through the Transwell was dramatically decreased compared with the number of Eca109-NC and untransfected Eca109 cells which migrated $(\mathrm{P}<0.001$, Fig. 5A). Similarly, in a Transwell invasion assay, the number of Eca109-shTIM-3 cells which invaded through the Transwell was significantly decreased compared with the number of Eca109-NC and untransfected Eca109 cells which invaded $(\mathrm{P}<0.001$, Fig. 5A). Similar results were obtained in the TE-1 cells $(\mathrm{P}<0.001$, Fig. 5B).

Downregulation of TIM-3 regulates the expression of metastasis-related molecules in the ESCC cells. MMPs and their inhibitors, termed TIMPs, have been reported to be closely associated with tumor growth, invasion and metastasis $(20,21)$. Among the MMP members, in particular MMP-9 plays a prominent role in ESCC cell invasion and metastasis $(22,23)$. Therefore, we investigated whether TIM-3 knockdown affects the expression of MMP-9 and TIMP-1 in Eca109 and TE-1 cells. qRT-PCR and western blotting revealed that TIM-3 depletion significantly 

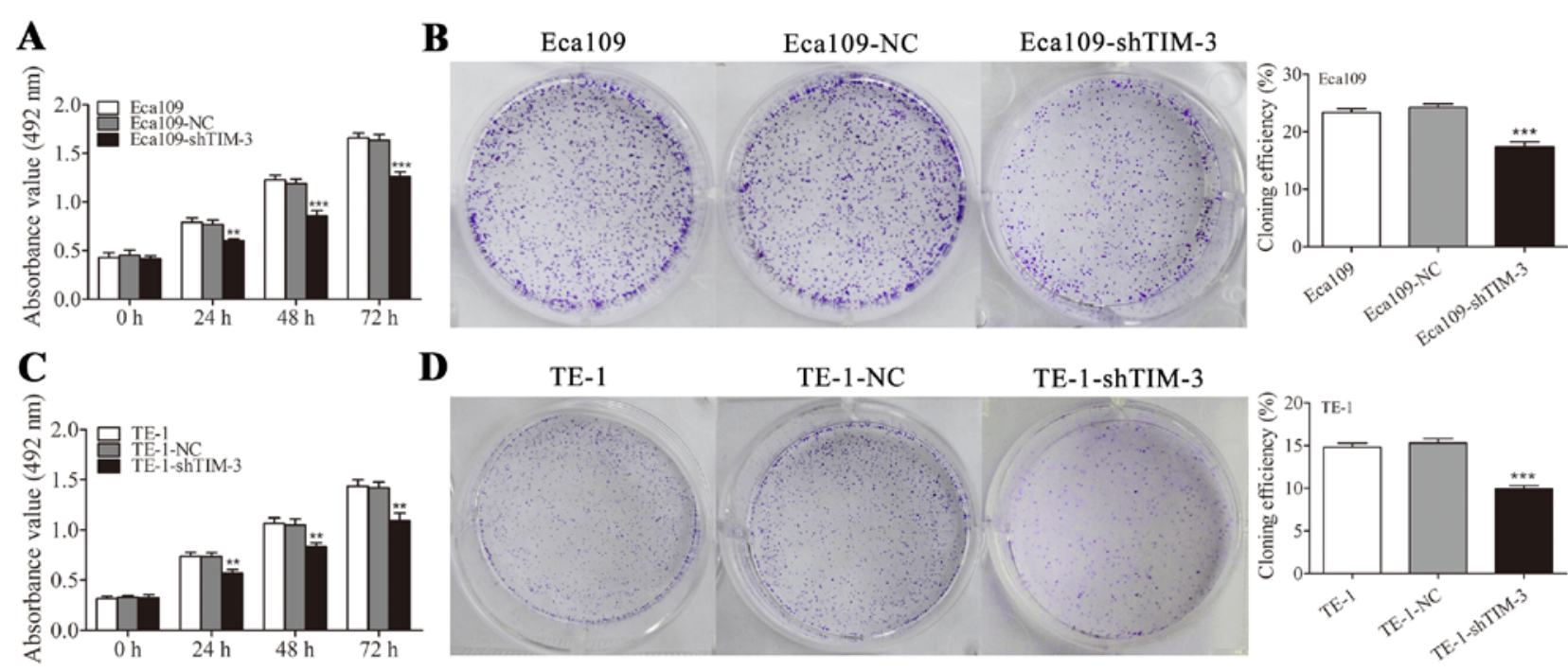

D $\quad$ TE-1

TE-1-NC

TE-1-shTIM-3

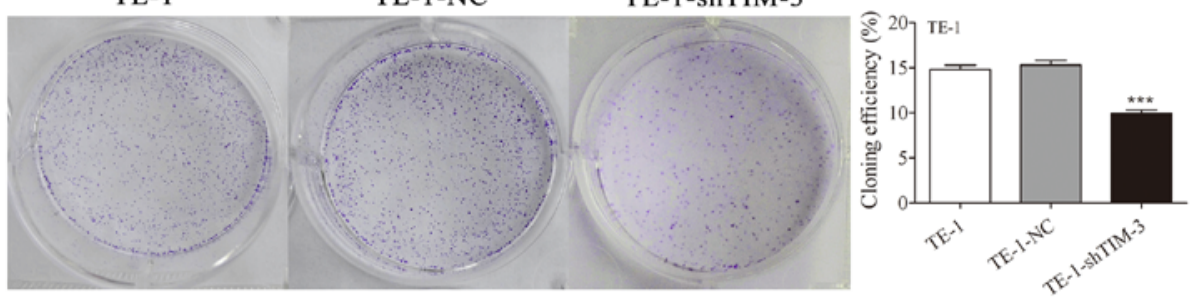

$\mathbf{E}$
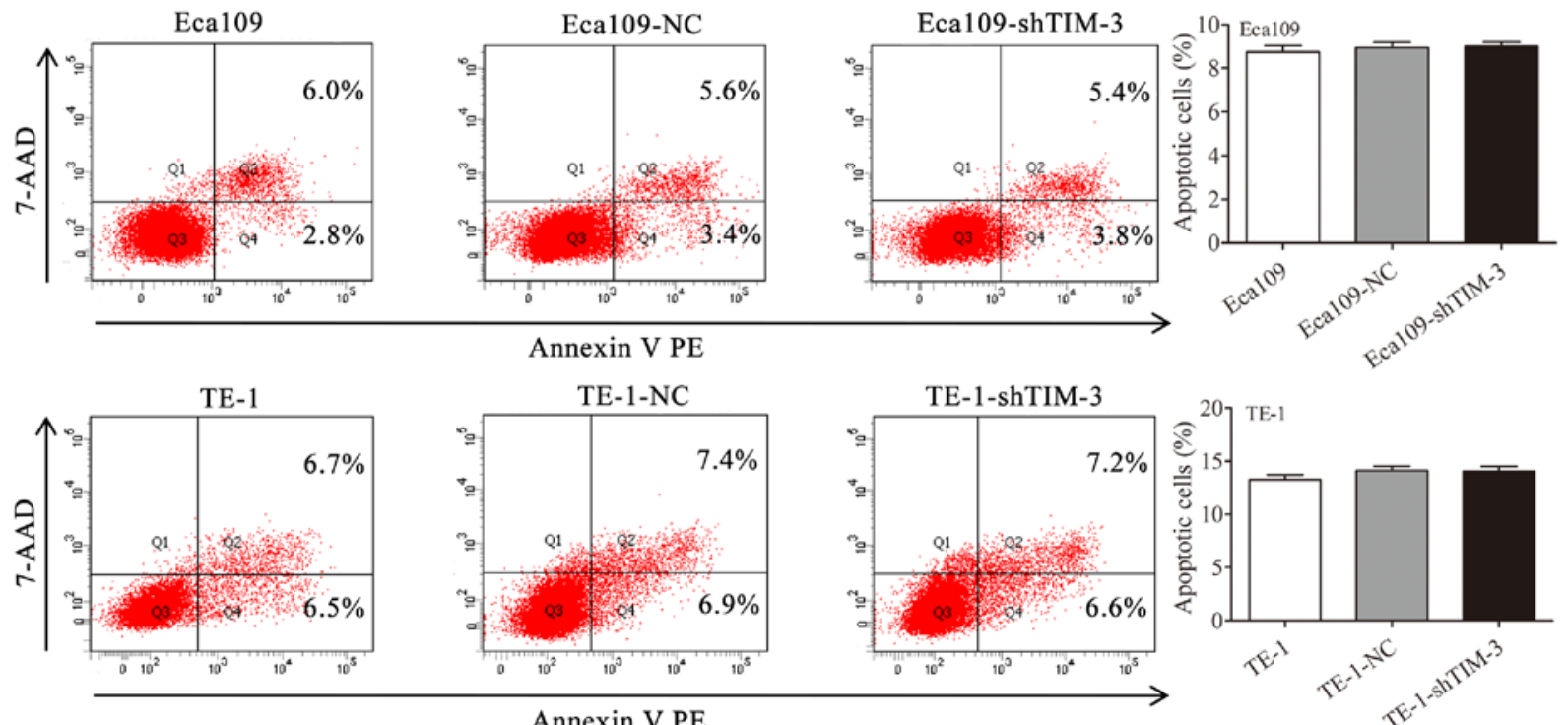

Figure 4. Downregulation of TIM-3 inhibits proliferation and clone formation ability but not apoptosis in ESCC cells. (A-D) TIM-3 knockdown inhibits cell proliferation and clone formation. (A) MTS assays in Eca109 cells. (B) Clone formation assays in Eca109 cells. (C) MTS assays in TE-1 cells. (D) Clone formation assays in TE-1 cells. (E) TIM-3 knockdown had no significant effect on the apoptosis in ESCC cells. Panels show Annexin V-PE/7-AAD staining in Eca109 (upper) and TE-1 (lower) cells. Data are shown as means $\pm \mathrm{SD}$. ${ }^{* *} \mathrm{P}<0.01,{ }^{* * * *} \mathrm{P}<0.001$ vs. the NC group. TIM-3, T-cell immunoglobulin and mucin domain-containing protein-3; ESCC, esophageal squamous cell carcinoma; NC, negative control.

downregulated MMP-9 and upregulated TIMP-1 in both cell lines (Fig. 6A-C).

Epithelial-mesenchymal transition (EMT) is a key step in the metastatic process of many solid tumors and represents a hallmark of this event (24). We aimed to ascertain whether TIM-3 depletion would inhibit the metastatic potential of ESCC cells in part by inhibiting EMT. Indeed, we found that TIM-3 depletion upregulated the epithelial marker E-cadherin and downregulated the mesenchymal markers N-cadherin and vimentin in both the Eca109 and TE-1 cells (Fig. 6A-C).

Downregulation of TIM-3 reverses EMT by suppressing Akt/GSK-3 $\beta /$ Snail signaling in the ESCC cells. Accumulating evidence has demonstrated that the Akt/GSK-3 $\beta /$ Snail signaling pathway can drive EMT to facilitate tumor progression $(25,26)$. To elucidate the potential signaling pathways involved in TIM-3-mediated EMT, we investigated the effects of TIM-3 knockdown on the Akt/GSK-3 $\beta /$ Snail signaling pathway. Western blotting revealed that the protein level of the active form of Akt (phosphorylated on Ser473), but not total Akt, the active form of GSK-3 $\beta$ (phosphorylated on Ser9), but not total GSK-3 $\beta$ were markedly decreased by knockdown of TIM-3 (Fig. 7). In addition, EMT-related transcription factor Snail was downregulated after TIM-3 knockdown (Fig. 7). These findings suggest that TIM-3 depletion acts via the Akt/GSK-3 $\beta /$ Snail signaling pathway to inhibit the EMT in ESCC.

\section{Discussion}

ESCC is a highly aggressive and fatal malignancy characterized by early local invasion and systemic metastasis (27). Despite aggressive treatment strategies, the overall survival rate of ESCC patients with metastasis and recurrence has seen 
$\mathbf{A}$
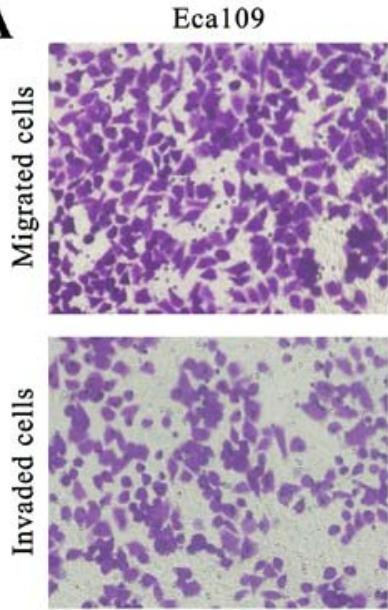

B
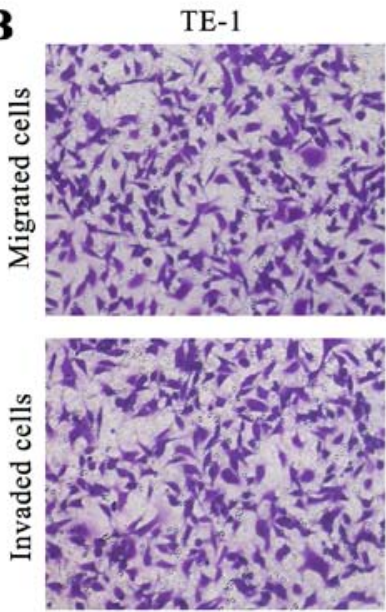

Eca109-NC
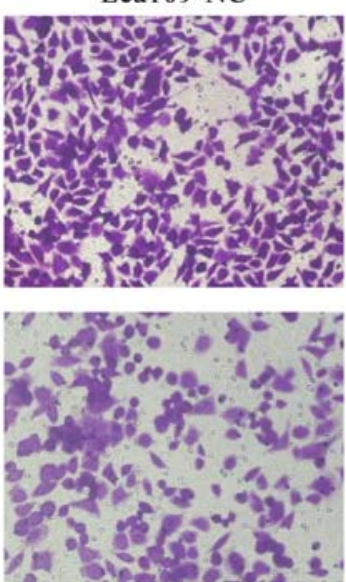

TE-1-NC
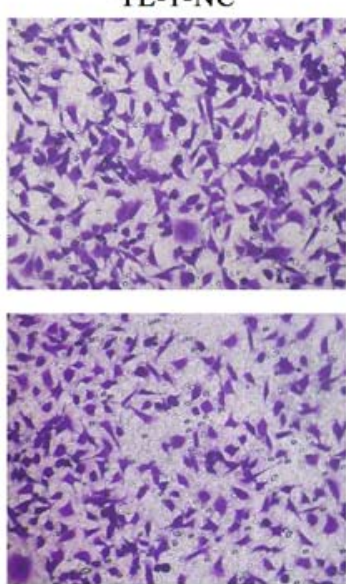

Eca109-shTIM-3
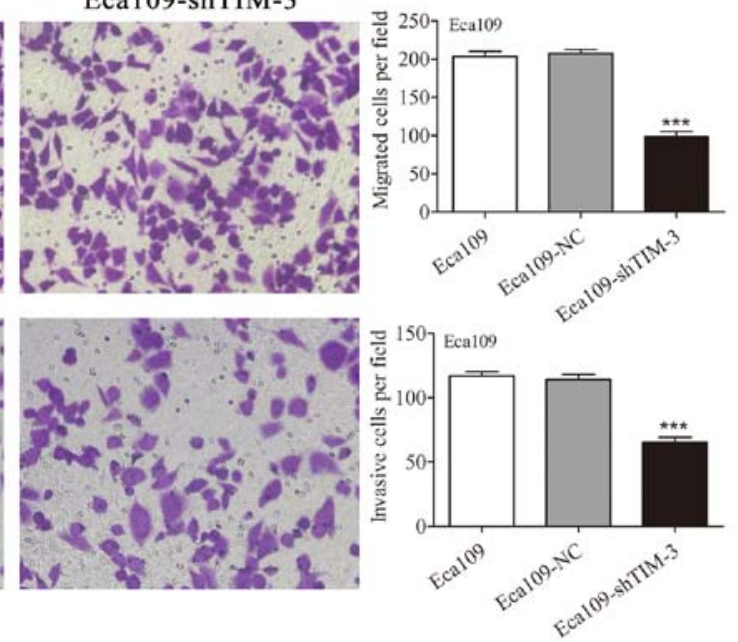

TE-1-shTIM-3
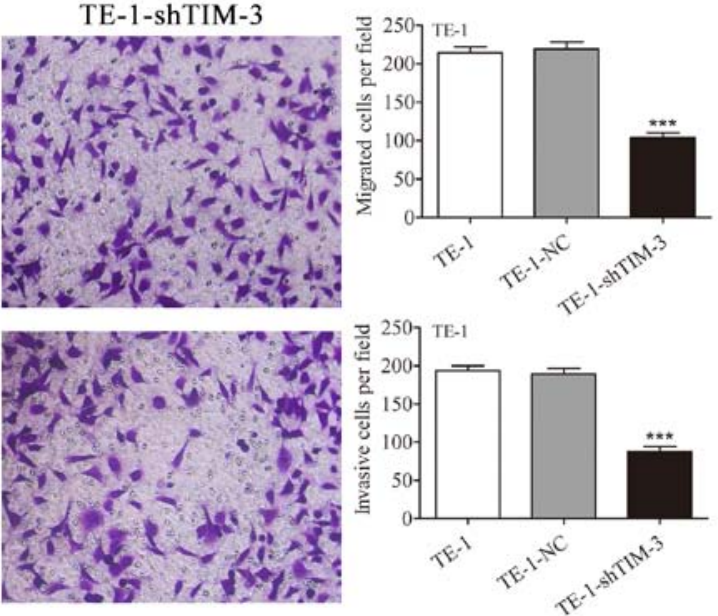

Figure 5. Downregulation of TIM-3 inhibits the migratory and invasive potential of ESCC cells. TIM-3 knockdown inhibits cell migration and invasion in (A) Eca109 and (B) TE-1 cells. Upper panels, Transwell migration assays; lower panels, Matrigel invasion assays. The migratory and invasive cells were visualized by microscopy (original magnification, $\mathrm{x} 200$ ). Data are shown as means $\pm \mathrm{SD}$. ${ }^{* * *} \mathrm{P}<0.001$ vs. the NC group. TIM-3, T-cell immunoglobulin and mucin domain-containing protein-3; ESCC, esophageal squamous cell carcinoma; NC, negative control.

no significant improvement $(28,29)$. TIM-3, a negative immune regulator, has been shown to have prognostic and functional significance in several types of human cancers $(30,31)$. Therefore, we sought to investigate whether TIM-3 may play a role in human ESCC. Our results with the patient tissues suggested that TIM-3 was upregulated in the ESCC tumors, and our study on the ESCC cell lines showed that downregulation of TIM-3 inhibited cell motility and invasion and reversed EMT by suppressing the Akt/GSK-3 $\beta /$ Snail signaling pathway. These findings suggest that TIM-3 may serve as a potential target of molecular therapies to inhibit ESCC aggression and metastasis.

In the present study, we report, for the first time, that TIM-3 was expressed in both ESCC tissue sections and ESCC cell lines. In line with our study, two recent studies identified that TIM-3 was expressed on leukemic stem cells (LSCs) in patients with acute myeloid leukemia $(32,33)$. Meanwhile, Wiener et al (34) found that TIM-3 was expressed not only on mast cells around melanomas, but also on tumor cells in tissue sections and human melanoma cell lines WM35 and HT168-M1. We further found that the expression level of TIM-3 was significantly higher in ESCC tissues than that in the matched adjacent normal tissues at both the mRNA and protein levels, which suggests that TIM-3 overexpression might correlate with the carcinogenesis of ESCC. In addition, further analysis demonstrated that TIM-3 expression was clearly associated with lymph node metastasis, TNM stage, and depth of tumor invasion, suggesting that TIM-3 is involved in ESCC progression and metastasis. Since we found a significantly worse overall survival rate for patients with high TIM-3 expression, our results also raise the possibility that high TIM-3 expression may serve as a marker of poor prognosis for patients with ESCC. Consistently, similar results have already been reported for cervical (31), lung (35) and clear cell renal cancer $(36,37)$.

To probe the potential biological functions of upregulated TIM-3 in ESCC, we generated stable Eca109-shTIM-3 and TE-1-shTIM-3 cell lines in which endogenous TIM-3 was knocked down by shRNA. The current in vitro experiments provided evidence that TIM-3 knockdown inhibited the proliferation, migration and invasion of both Eca109 and TE-1 cell lines. Consistent with our results, Yuan et al (36) demonstrated that knockdown of TIM-3 suppressed the proliferation and invasion of clear cell renal carcinoma (ccRCC) cell lines 
$\mathbf{A}$

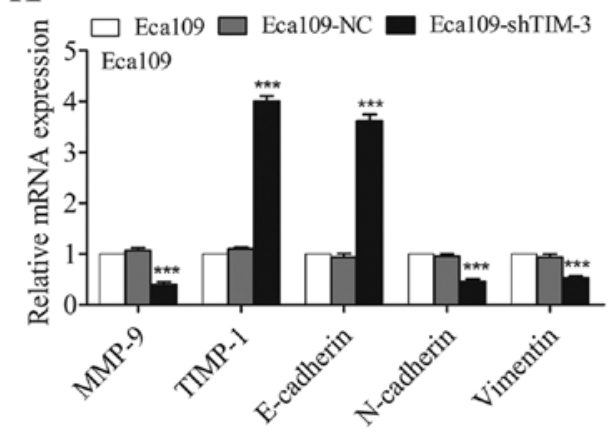

B

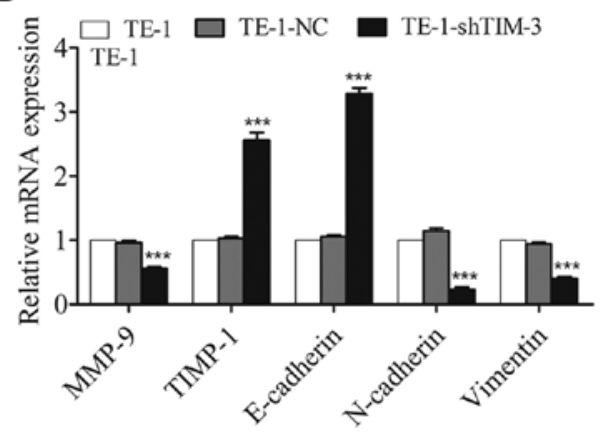

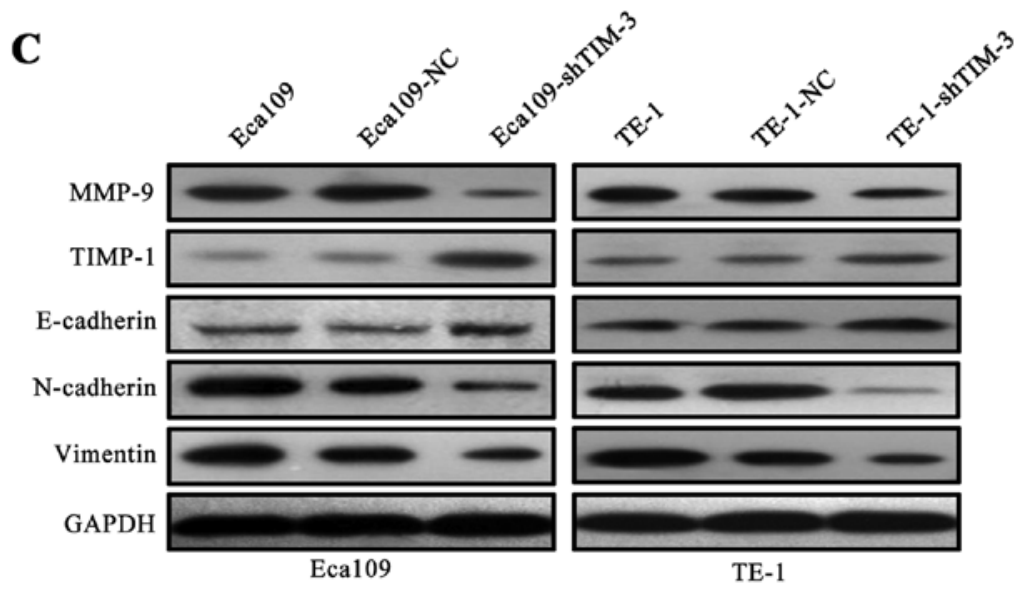

Figure 6. Downregulation of TIM-3 regulates the expression of metastasis-related molecules in ESCC cells. (A and B) The mRNA expression of the indicated genes MMP-9, TIMP-1, E-cadherin, N-cadherin, and vimentin were determined using qRT-PCR in (A) Eca109 and (B) TE-1 cells. (C) Levels of the corresponding proteins were evaluated using western blotting. GAPDH was used for normalization. Data are shown as means $\pm \mathrm{SD}$. ${ }^{* * *} \mathrm{P}<0.001 \mathrm{vs}$. the $\mathrm{NC}$ group. TIM-3, T-cell immunoglobulin and mucin domain-containing protein-3; ESCC, esophageal squamous cell carcinoma; MMP, matrix metalloproteinase; TIMP, tissue inhibitor of metalloproteinase; GAPDH, glyceraldehyde-3-phosphate dehydrogenase; NC, negative control.

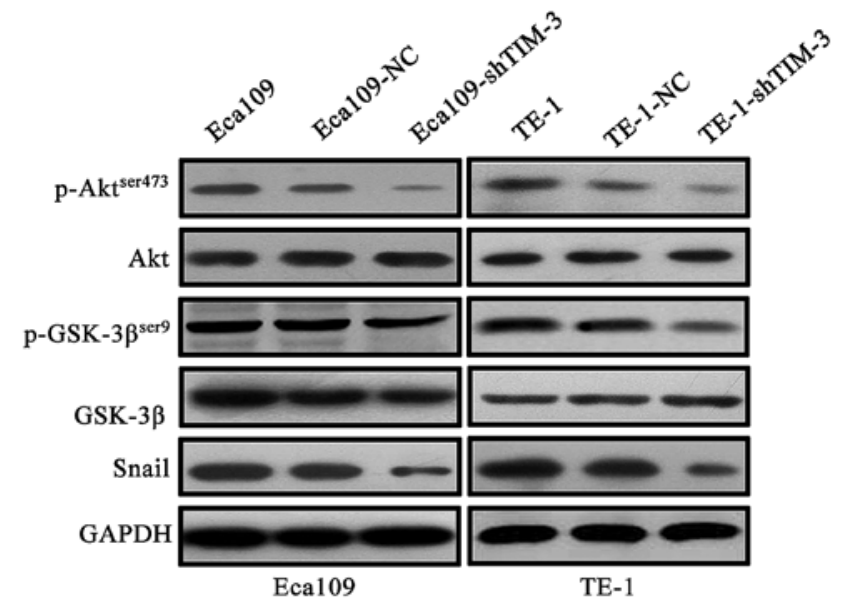

Figure 7. Downregulation of TIM-3 inhibits the Akt/GSK-3ß/Snail signaling pathway. Levels of Akt, p-Akt ${ }^{\text {ser473 }}$, GSK-3 $\beta$, p-GSK-3 $\beta^{\text {ser9 }}$, and Snail were assessed in Eca109 and TE-1 cells using western blotting. TIM-3, T-cell immunoglobulin and mucin domain-containing protein-3.

A498 and 769P. Meanwhile, Cao et al (31) also suggested that downregulation of TIM-3 significantly decreased the migration and invasion of HeLa cells. Our findings suggest that TIM-3 promotes the invasion and metastasis of ESCC. To test this more directly, we examined the effects of TIM-3 knockdown on expression of metastasis-related molecules. One was MMP-9, which helps degrade the extracellular matrix to allow tumor cell invasion and metastasis (38,39). TIM-3 depletion significantly decreased levels of MMP-9 mRNA and protein in the Eca109 and TE-1 cells, which at least partly might explain why TIM-3 knockdown reduced the invasive potential of ESCC cells in our experiments. MMP activity is negatively controlled by TIMPs (40), and imbalance between MMPs and TIMPs can facilitate cancer progression (41). Consistent with our hypothesis that TIM-3 helps drive ESCC metastasis, we found that knockdown of TIM-3 upregulated TIMP-1 expression, presumably reducing MMP-9 activity.

EMT is a key event during cancer metastasis, which confers an aggressive phenotype to tumor cells (42). A variety of molecular events have been identified to participate in EMT, but whether TIM-3 is involved in EMT and cancer metastasis remains unclear. We hypothesized that TIM-3 could promote EMT and ESCC metastasis. To test this hypothesis, we examined the effects of TIM-3 knockdown on expression of EMT-associated molecules. At the molecular level, EMT involves downregulation of the intercellular adhesion molecule E-cadherin and upregulation of various mesenchymal markers, including $\mathrm{N}$-cadherin, vimentin and fibronectin (43). Here, we showed that TIM-3 depletion upregulated E-cadherin and downregulated $\mathrm{N}$-cadherin and vimentin. In further support of this hypothesis, we found that TIM-3 depletion downregulated Snail, a nuclear transcription factor involved in EMT. Our findings are consistent with a study suggesting that TIM-3 may trigger the process of EMT to promote tumor development in 
human osteosarcoma (44). These results indicate that TIM-3 promoted ESCC metastasis in part by regulating EMT. The ability of Snail to trigger EMT appears to depend on phosphorylation of Akt, which in turn phosphorylates GSK-3 $\beta(25,45)$. Indeed, the activated Akt/GSK-3 $\beta /$ Snail signaling pathway has been shown to trigger EMT and contribute to an aggressive phenotype in several human malignant tumors (46-49). We showed that TIM-3 depletion significantly reduced levels of p-AKT, p-GSK-3 $\beta$ and Snail, further supporting the hypothesis that TIM-3 helps drive EMT in ESCC and suggesting that TIM-3 acts via the Akt/GSK-3 $\beta /$ Snail signaling pathway to do so.

In conclusion, this study revealed that TIM-3 plays a crucial role in ESCC metastasis by inducing EMT via, at least partially, the Akt/GSK-3 $\beta /$ Snail signaling pathway. Moreover, the characterization of TIM-3 may contribute to the identification of a potential therapeutic target and valuable prognostic biomarker for patients with ESCC.

\section{Acknowledgements}

This study was supported by the National Natural Science Foundation of China (no. 81173611).

\section{References}

1. Vay C, Hosch SB, Stoecklein NH, Klein CA, Vallböhmer D, Link BC, Yekebas EF, Izbicki JR, Knoefel WT and Scheunemann P: Integrin expression in esophageal squamous cell carcinoma: Loss of the physiological integrin expression pattern correlates with disease progression. PLoS One 9: e109026, 2014

2. Pennathur A, Gibson MK, Jobe BA and Luketich JD: Oesophageal carcinoma. Lancet 381: 400-412, 2013.

3. Torre LA, Bray F, Siegel RL, Ferlay J, Lortet-Tieulent J and Jemal A: Global cancer statistics, 2012. CA Cancer J Clin 65: 87-108, 2015.

4. Ferlay J, Soerjomataram I, Dikshit R, Eser S, Mathers C, Rebelo M, Parkin DM, Forman D and Bray F: Cancer incidence and mortality worldwide: Sources, methods and major patterns in GLOBOCAN 2012. Int J Cancer 136: E359-E386, 2015.

5. Siegel RL, Miller KD and Jemal A: Cancer statistics, 2015. CA Cancer J Clin 65: 5-29, 2015.

6. Chen T, Wang C, Wu F, Zhang X, Yang H, Deng X, He Q, Li W and Li G: Altered localization of p120 catenin in the cytoplasm rather than the membrane correlates with poor prognosis in esophageal squamous cell carcinoma. PLoS One 10: e0118645, 2015.

7. Xu Y, Wang J, Qiu M, Xu L, Li M, Jiang F, Yin R and Xu L: Upregulation of the long noncoding RNA TUG1 promotes proliferation and migration of esophageal squamous cell carcinoma. Tumour Biol 36: 1643-1651, 2015.

8. McIntire JJ, Umetsu SE, Akbari O, Potter M, Kuchroo VK, Barsh GS, Freeman GJ, Umetsu DT and DeKruyff RH: Identification of Tapr (an airway hyperreactivity regulatory locus) and the linked Tim gene family. Nat Immunol 2: 1109-1116, 2001.

9. Monney L, Sabatos CA, Gaglia JL, Ryu A, Waldner H, Chernova T, Manning S, Greenfield EA, Coyle AJ, Sobel RA, et al: Th1-specific cell surface protein Tim-3 regulates macrophage activation and severity of an autoimmune disease. Nature 415: 536-541, 2002.

10. Zhu C, Anderson AC, Schubart A, Xiong H, Imitola J, Khoury SJ, Zheng XX, Strom TB and Kuchroo VK: The Tim-3 ligand galectin-9 negatively regulates $T$ helper type 1 immunity. Nat Immunol 6: 1245-1252, 2005.

11. Li H, Wu K, Tao K, Chen L, Zheng Q, Lu X, Liu J, Shi L, Liu C, Wang G, et al: Tim-3/galectin-9 signaling pathway mediates T-cell dysfunction and predicts poor prognosis in patients with hepatitis B virus-associated hepatocellular carcinoma. Hepatology 56: 1342-1351, 2012.

12. Fourcade J, Sun Z, Benallaoua M, Guillaume P, Luescher IF, Sander C, Kirkwood JM, Kuchroo V and Zarour HM: Upregulation of Tim-3 and PD-1 expression is associated with tumor antigen-specific $\mathrm{CD} 8^{+} \mathrm{T}$ cell dysfunction in melanoma patients. J Exp Med 207: 2175-2186, 2010.
13. Gao X, Zhu Y, Li G, Huang H, Zhang G, Wang F, Sun J, Yang Q, Zhang $X$ and Lu B: TIM-3 expression characterizes regulatory $\mathrm{T}$ cells in tumor tissues and is associated with lung cancer progression. PLoS One 7: e30676, 2012.

14. Piao YR, Jin ZH, Yuan KC and Jin XS: Analysis of Tim-3 as a therapeutic target in prostate cancer. Tumour Biol 35: 11409-11414, 2014.

15. Cheng G, Li M, Wu J, Ji M, Fang C, Shi H, Zhu D, Chen L, Zhao J, Shi L, et al: Expression of Tim-3 in gastric cancer tissue and its relationship with prognosis. Int J Clin Exp Pathol 8: 9452-9457, 2015.

16. Yang M, Yu Q, Liu J, Fu W, Cao Y, Yu L, Shao S, Wang X, Niu $\mathrm{H}$ and Wang Y: T-cell immunoglobulin mucin-3 expression in bladder urothelial carcinoma: Clinicopathologic correlations and association with survival. J Surg Oncol 112: 430-435, 2015.

17. Ling XL, Zhang T, Hou XM and Zhao D: Clinicopathological significance of fascin-1 expression in patients with non-small cell lung cancer. Onco Targets Ther 8: 1589-1595, 2015.

18. Li J, Huang H, Sun L, Yang M, Pan C, Chen W, Wu D, Lin Z, Zeng C, Yao Y, et al: MiR-21 indicates poor prognosis in tongue squamous cell carcinomas as an apoptosis inhibitor. Clin Cancer Res 15: 3998-4008, 2009.

19. Loos M, Hedderich DM, Ottenhausen M, Giese NA, Laschinger M, Esposito I, Kleeff J and Friess $\mathrm{H}$ : Expression of the costimulatory molecule B7-H3 is associated with prolonged survival in human pancreatic cancer. BMC Cancer 9: 463, 2009.

20. Kessenbrock K, Plaks V and Werb Z: Matrix metalloproteinases: Regulators of the tumor microenvironment. Cell 141: 52-67, 2010.

21. Herszényi L, Hritz I, Lakatos G, Varga MZ and Tulassay Z: The behavior of matrix metalloproteinases and their inhibitors in colorectal cancer. Int J Mol Sci 13: 13240-13263, 2012.

22. Chen Y, Jiang T, Mao A and Xu J: Esophageal cancer stem cells express PLGF to increase cancer invasion through MMP9 activation. Tumour Biol 35: 12749-12755, 2014.

23. Zhao G, Kang J, Jiao K, Xu G, Yang L, Tang S, Zhang H, Wang Y, Nie Y, Wu K, et al: High expression of GRP78 promotes invasion and metastases in patients with esophageal squamous cell carcinoma. Dig Dis Sci 60: 2690-2699, 2015.

24. Wang Y, Shi J, Chai K, Ying X and Zhou BP: The role of snail in EMT and tumorigenesis. Curr Cancer Drug Targets 13: 963-972, 2013.

25. Xu W, Yang Z and Lu N: A new role for the PI3K/Akt signaling pathway in the epithelial-mesenchymal transition. Cell Adhes Migr 9: 317-324, 2015.

26. Wen W, Ding J, Sun W, Fu J, Chen Y, Wu K, Ning B, Han T, Huang L, Chen C, et al: Cyclin G1-mediated epithelial-mesenchymal transition via phosphoinositide 3-kinase/Akt signaling facilitates liver cancer progression. Hepatology 55: 1787-1798, 2012.

27. Zhu M, Xu Y, Mao X, Gao Y, Shao L and Yan F: Overexpression of metastasis-associated in colon cancer-1 associated with poor prognosis in patients with esophageal cancer. Pathol Oncol Res 19: 749-753, 2013

28. Mohamed A, El-Rayes B, Khuri FR and Saba NF: Targeted therapies in metastatic esophageal cancer: Advances over the past decade. Crit Rev Oncol Hematol 91: 186-196, 2014.

29. Li LY, Jiang H, Xie YM, Liao LD, Cao HH, Xu XE, Chen B, Zeng FM, Zhang YL, Du ZP, et al: Macrolide analog F806 suppresses esophageal squamous cell carcinoma (ESCC) by blocking $\beta 1$ integrin activation. Oncotarget 6: 15940-15952, 2015.

30. Anderson AC: Tim-3: An emerging target in the cancer immunotherapy landscape. Cancer Immunol Res 2: 393-398, 2014.

31. Cao Y, Zhou X, Huang X, Li Q, Gao L, Jiang L, Huang M and Zhou J: Tim-3 expression in cervical cancer promotes tumor metastasis. PLoS One 8: e53834, 2013.

32. Kikushige Y, Shima T, Takayanagi S, Urata S, Miyamoto T, Iwasaki H, Takenaka K, Teshima T, Tanaka T, Inagaki Y, et al: TIM-3 is a promising target to selectively kill acute myeloid leukemia stem cells. Cell Stem Cell 7: 708-717, 2010.

33. Jan M, Chao MP, Cha AC, Alizadeh AA, Gentles AJ, Weissman IL and Majeti R: Prospective separation of normal and leukemic stem cells based on differential expression of TIM3, a human acute myeloid leukemia stem cell marker. Proc Natl Acad Sci USA 108: 5009-5014, 2011.

34. Wiener Z, Kohalmi B, Pocza P, Jeager J, Tolgyesi G, Toth S, Gorbe E, Papp Z and Falus A: TIM-3 is expressed in melanoma cells and is upregulated in TGF-beta stimulated mast cells. J Invest Dermatol 127: 906-914, 2007. 
35. Zhuang X, Zhang X, Xia X, Zhang C, Liang X, Gao L, Zhang X and Ma C: Ectopic expression of TIM-3 in lung cancers: A potential independent prognostic factor for patients with NSCLC. Am J Clin Pathol 137: 978-985, 2012.

36. Yuan J, Jiang B, Zhao H and Huang Q: Prognostic implication of TIM-3 in clear cell renal cell carcinoma. Neoplasma 61: 35-40, 2014.

37. Komohara Y, Morita T, Annan DA, Horlad H, Ohnishi K, Yamada S, Nakayama T, Kitada S, Suzu S, Kinoshita I, et al: The coordinated actions of TIM-3 on cancer and myeloid cells in the regulation of tumorigenicity and clinical prognosis in clear cell renal cell carcinomas. Cancer Immunol Res 3: 999-1007, 2015.

38. Hadler-Olsen E, Winberg JO and Uhlin-Hansen L: Matrix metalloproteinases in cancer: Their value as diagnostic and prognostic markers and therapeutic targets. Tumour Biol 34: 2041-2051, 2013.

39. Zhang X, Wang Y, Yamamoto G and Tachikawa T: Expression of matrix metalloproteinases MMP-2, MMP-9 and their tissue inhibitors TIMP-1 and TIMP-2 in the epithelium and stroma of salivary gland pleomorphic adenomas. Histopathology 55: 250-260, 2009

40. Jinga DC, Blidaru A, Condrea I, Ardeleanu C, Dragomir C, Szegli G, Stefanescu M and Matache C: MMP-9 and MMP-2 gelatinases and TIMP-1 and TIMP-2 inhibitors in breast cancer: Correlations with prognostic factors. J Cell Mol Med 10: 499-510, 2006.

41. Groblewska M, Siewko M, Mroczko B and Szmitkowski M: The role of matrix metalloproteinases (MMPs) and their inhibitors (TIMPs) in the development of esophageal cancer. Folia Histochem Cytobiol 50: 12-19, 2012.

42. Davis FM, Stewart TA, Thompson EW and Monteith GR Targeting EMT in cancer: Opportunities for pharmacological intervention. Trends Pharmacol Sci 35: 479-488, 2014.
43. Wu WL, Wang WY, Yao WQ and Li GD: Suppressive effects of microRNA-16 on the proliferation, invasion and metastasis of hepatocellular carcinoma cells. Int J Mol Med 36: 1713-1719, 2015.

44. Shang Y, Li Z, Li H, Xia H and Lin Z: TIM-3 expression in human osteosarcoma: Correlation with the expression of epithelial-mesenchymal transition-specific biomarkers. Oncol Lett 6: 490-494, 2013.

45. Zhou BP, Deng J, Xia W, Xu J, Li YM, Gunduz M and Hung MC: Dual regulation of Snail by GSK-3 $\beta$-mediated phosphorylation in control of epithelial-mesenchymal transition. Nat Cell Biol 6: 931-940, 2004

46. Liu A, Shao C, Jin G, Liu R, Hao J, Song B, Ouyang L and $\mathrm{Hu}$ X: miR-208-induced epithelial to mesenchymal transition of pancreatic cancer cells promotes cell metastasis and invasion. Cell Biochem Biophys 69: 341-346, 2014.

47. Liu L, Dai Y, Chen J, Zeng T, Li Y, Chen L, Zhu YH, Li J, Li Y, Ma S, et al: Maelstrom promotes hepatocellular carcinoma metastasis by inducing epithelial-mesenchymal transition by way of Akt/GSK-3ß/Snail signaling. Hepatology 59: 531-543, 2014.

48. Zhang J, Wei J, Lu J, Tong Z, Liao B, Yu B, Zheng F, Huang X, Chen Z, Fang Y, et al: Overexpression of Rab25 contributes to metastasis of bladder cancer through induction of epithelial-mesenchymal transition and activation of Akt/GSK-3 $\beta /$ Snail signaling. Carcinogenesis 34: 2401-2408, 2013.

49. Li Q, Wu J, Wei P, Xu Y, Zhuo C, Wang Y, Li D and Cai S: Overexpression of forkhead Box C2 promotes tumor metastasis and indicates poor prognosis in colon cancer via regulating epithelial-mesenchymal transition. Am J Cancer Res 5: 2022-2034, 2015. 